

\section{CATCHING A WAVE}

Physicists bagged some big game this year. On 11 February, researchers announced that they had finally sensed the ripples in the structure of space-time known as gravitational waves - capping a decades-long quest. The signal, spotted in September 2015 by the twin detectors of the Laser Interferometer Gravitational-Wave Observatory (LIGO) in Louisiana and Washington state, came from the merger of two black holes some 1 billion years before.

The announcement was a stunning affirmation of Albert Einstein's general theory of relativity, almost 100 years after he had published it. And it provided the most direct evidence yet that black holes - another prediction of Einstein's theory - exist. Astrophysicists hailed LIGO's feat as a triumph, saying that it heralded a new way of observing the cosmos, enabling the detection of phenomena that might not be picked up by other means.

Just weeks after the LIGO announcement, another experiment demonstrated that the search for gravitational waves could one day occur in space. The European Space Agency's LISA Pathfinder mission tested technologies for a future trio of probes that would sense gravitational waves coming from even larger and more-distant objects than the ones LIGO observed.

Particle physicists were not so lucky. They spent much of the year holding their collective breath. Two separate experiments at the Large Hadron Collider near Geneva, Switzerland, had reported anomalous measurements in late 2015 that suggested the existence of a particle six times as massive as the Higgs boson.

At the time, experimenters warned that the anomalies could be statistical flukes. And more data released in August confirmed this. By then, theoreticians had written hundreds of papers in attempts to interpret the original data with a zoo of possible models.

\section{NEW WORLD ORDER}

A tumultuous US presidential campaign ended in a surprise victory for Republican businessman Donald Trump in November. Researchers struggled to understand how a Trump administration would treat science - in part, because it did not feature prominently on the campaign trail. Still, some of Trump's views were clear: he has alleged that climate change is a hoax perpetrated by the Chinese, and has pledged to withdraw the United States from the Paris climate agreement. He has also suggested a link between autism and childhood vaccinations.

As Trump's administration began to take shape, researchers started to lobby against what they saw as an incoming president with little

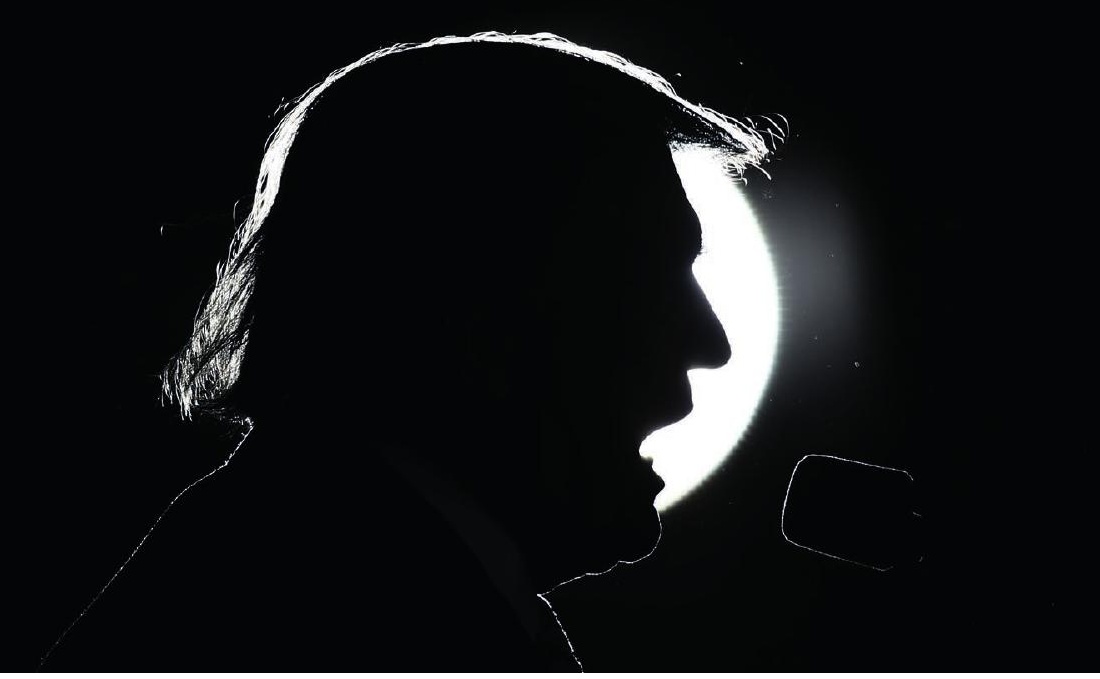

President-elect Donald Trump on the campaign trail in October.

use for science. In late November, more than 2,300 scientists including 22 Nobel laureates - sent a letter to Trump urging him to "adhere to high standards of scientific integrity and independence in responding to current and emerging public health and environmental health threats".

The United Kingdom's 23 June vote to leave the European Union shook the country's scientific community. Researchers remain worried about the fate of millions of euros in annual research funding from the EU and the immigration status of UK university staff from nonBritish EU nations. Some UK researchers have reported being cut out of EU collaborations, and some foreign scientists say that they feel so unwelcome that they plan to leave the country. In happier news, the UK government - led by a cabinet that came to power in the wake of the Brexit vote - announced a surprise funding boost in November worth $£ 2$ billion (US\$2.5 billion) annually by 2020 .

A failed military coup in Turkey in July spelt upheaval of a different kind for academics: the Council of Higher Education promptly fired more than 1,500 university deans. About $58 \%$ of the positions have since been refilled by their former occupants. But more than 6,500 professors have been dismissed on suspicion of involvement in the coup. Human-rights groups say that many of the dismissed are innocent.

Political and economic woes rocked Venezuela, Brazil and South Africa this year - and did not spare researchers. Rolling blackouts, food queues and increasing violence prompted hundreds of scientists to leave Venezuela's universities, and, in some cases, the country. Brazil's researchers are facing drastic budget cuts and the demotion of the science ministry, and protested against proposals to freeze federal science spending and weaken the country's environmental laws. And austerity measures in South Africa have led to chronic underfunding of universities and triggered a rash of campus protests and violence.

\section{TO B OLLY GO}

In the year that saw the 50th anniversary of Star Trek, technical glitches set back several space missions - but there were also notable victories. In March, the Japan Aerospace Exploration Agency's flagship Hitomi X-ray astronomy satellite failed just weeks after launch. Investigators determined that a software error had caused the spacecraft to rotate out of control and break apart. In July, NASA's Juno probe arrived at Jupiter, but problems with its main engine delayed the rocket firing

A sunlit part of Jupiter. 


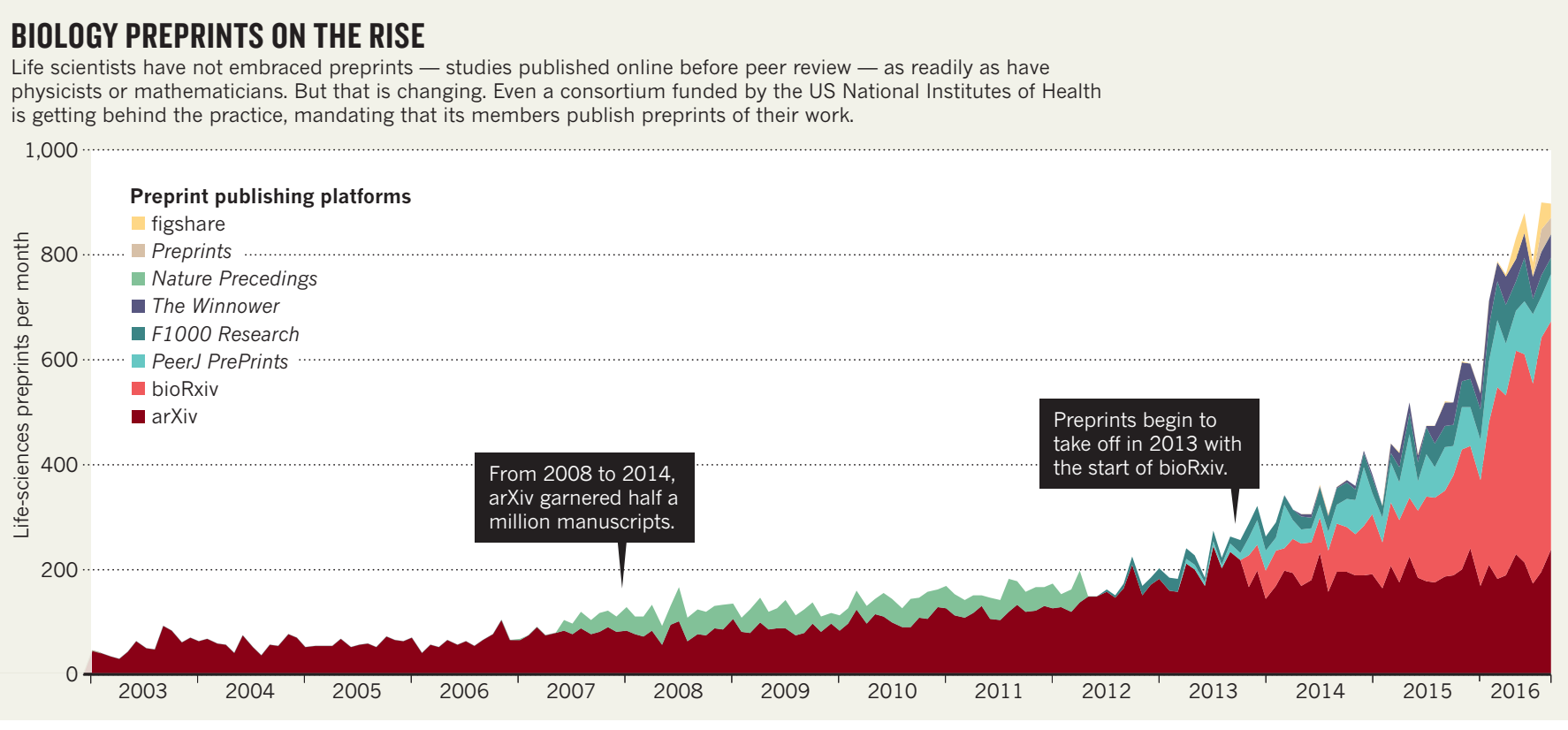

that would have shrunk its orbit into a tighter ellipse around the planet. The spacecraft continues to gather data on Jupiter's atmosphere and magnetosphere on every fly-by - just more slowly than planned.

Meanwhile, the European Space Agency (ESA) mourned the end of two probes. In October, the Schiaparelli lander - part of the ESA's ExoMars mission - smashed onto the red planet's surface after a measurement error caused its parachute and braking rockets to deploy at the wrong times. But at least its companion spacecraft managed to enter orbit around Mars. ESA's other loss was sad for some scientists, but deliberate. The pioneering Rosetta spacecraft crashed onto the surface of Comet 67P/Churyumov-Gerasimenko in September as planned, radioing back close-up images before it lost contact — and bringing the mission to an end.

Rising space power China garnered several wins. In August, it launched the first ever quantum satellite, aimed at testing ways to extend secure quantum communication into space. In September, the country completed construction on the world's largest single-dish telescope, the Five-hundred-meter Aperture Spherical Radio Telescope in the southwestern province of Guizhou. And in November, China launched the Long March 5 rocket, one of the world's most powerful. It is meant to send people, rovers and heavy-duty planetary probes into space.

Finally, two Chinese astronauts broke their country's record for the longest-duration space mission when they spent a month aboard the Tiangong 2 space laboratory in October and November.

\section{CRISPR IN COURT}

The development of new applications for the genome-editing tool CRISPR-Cas 9 continued apace. On 28 October, a patient with lung cancer at West China Hospital in Chengdu became the first person to be treated with cells edited using CRISPR-Cas9. As part of a clinical trial, researchers disabled a gene that normally holds a cell's immune system in check, in the hope that the edited cells would mount an immune response against the cancer. More cancer trials using treatments based on CRISPR-Cas9 are expected in the United States and China next year.

But the commercial landscape for CRISPR-Cas9 therapies remains uncertain. The battle over US patent rights to the gene-editing technique reached fever pitch after the US Patent and Trademark Office declared an 'interference' proceeding between two research teams in January. The proceeding, which could conclude early next year, aims to determine who first invented the technique. Each team applied for patents that could be crucial for commercial applications.

Meanwhile, research using CRISPR-Cas9 in human embryos expanded this year. It is a controversial area of research that has raised concerns about the potential for designer babies - but regulators in some countries have approved projects in this field. Teams in China, the United Kingdom and Sweden announced their intentions to use the technique to optimize its use in embryos and to study human development. Work in the United States is expected to follow, despite a prohibition on the use of federal funds to study human embryos or to modify human eggs or sperm.

\section{CLIMATE CRUNCH}

Representatives of a record 174 countries and the European Union gathered on Earth Day, 22 April, to sign the international climate agreement forged in Paris in December 2015. But for the accord to come into force, more than 55 countries accounting for at least $55 \%$ of global greenhouse-gas emissions needed to submit ratification or acceptance documents.

The biggest boost came in September, when the United States and China - which together account for $38 \%$ of global emissions - formally joined the agreement. Brazil and 30 other countries joined a few weeks later, and the EU sealed the deal on 5 October.

The pact came into effect on 4 November.

But that wasn't the only global climate deal afoot. On 6 October, the United Nations' International Civil Aviation Organization curbed emissions from international flights. And on 15 October, 197 countries agreed to amend the Montreal Protocol - designed to protect the ozone layer - to phase out hydrofluorocarbons, powerful greenhouse gases commonly used in air conditioners. Countries also broke a four-year-long impasse on

Green lights illuminate the Eiffel Tower to celebrate the Paris climate agreement. 
28 October to create the world's largest marine reserve in the Ross Sea off the coast of Antarctica.

All the while, global warming continued. An epic El Niño in the tropical Pacific Ocean helped set globaltemperature records in the first five months of the year. This put 2016 on track to become the third straight warmest year in a row. The blazing warmth prompted corals around the world to bleach, a process in which the stressed animals expel the algae that help to keep them alive. The El Niño faded away in May, but coral bleaching continued throughout the year and is expected to continue into 2017.

\section{ZIKA SPREADS}

In February, the World Health Organization (WHO) declared that clusters of birth defects linked to outbreaks of Zika virus in Brazil constituted a global public-health emergency. These birth defects included severe cases of microcephaly, a condition in which fetuses or newborns have abnormally small heads and brains.

But the expected explosion in microcephaly cases and other Zika-linked birth defects across the Americas has not materialized, despite the virus's spread across the continents.

Even in Brazil, extremely high rates of microcephaly remained confined to the country's northeast region - and researchers began to suspect the influence of confounding factors. In July, Brazilian authorities launched a study to find out whether environmental, socio-economic or biological elements, when combined with Zika infection, could explain the odd distribution of elevated rates. They expect preliminary results early next year.

On 18 November, the WHO declared the end of the international public-health emergency on the grounds that the link between Zika and birth defects had been established, and that the focus needed to shift to understanding the consequences of Zika infections, including the birth defects, and developing a vaccine.

Several ongoing international research projects should produce results next year on a number of Zika-related questions, such as what proportion of infected pregnant women go on to have babies with birth defects.

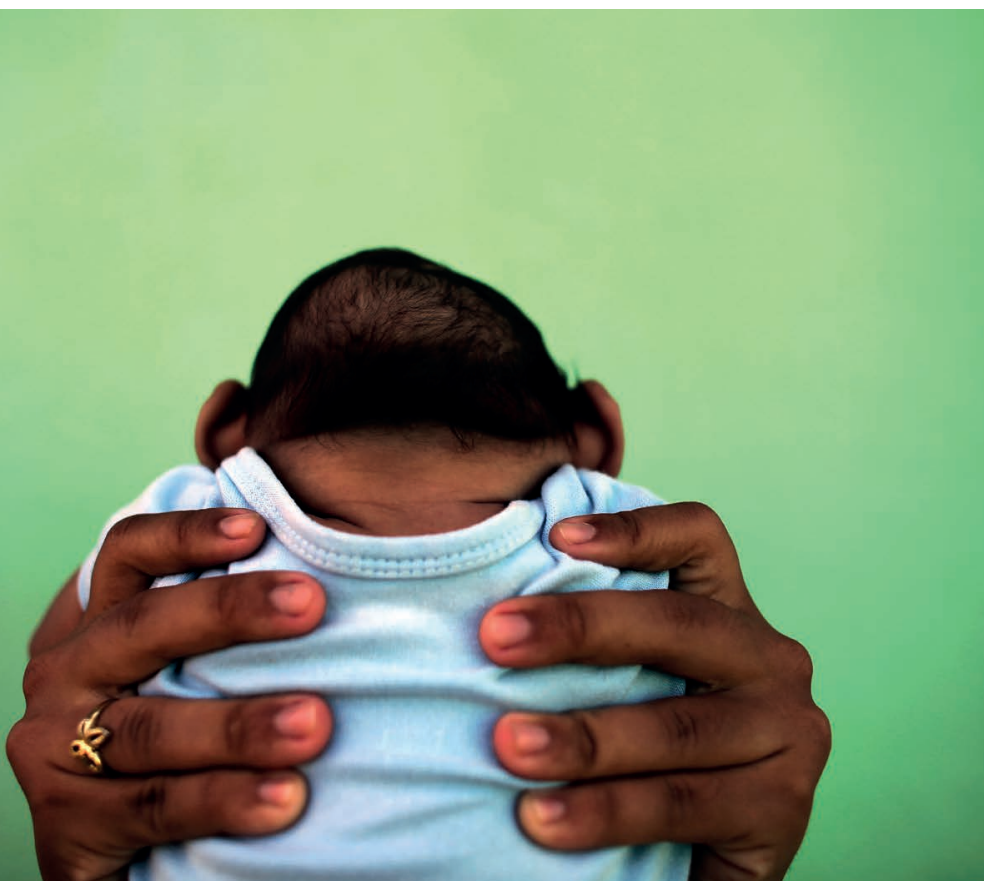

A four-month-old baby born in Brazil with microcephaly.

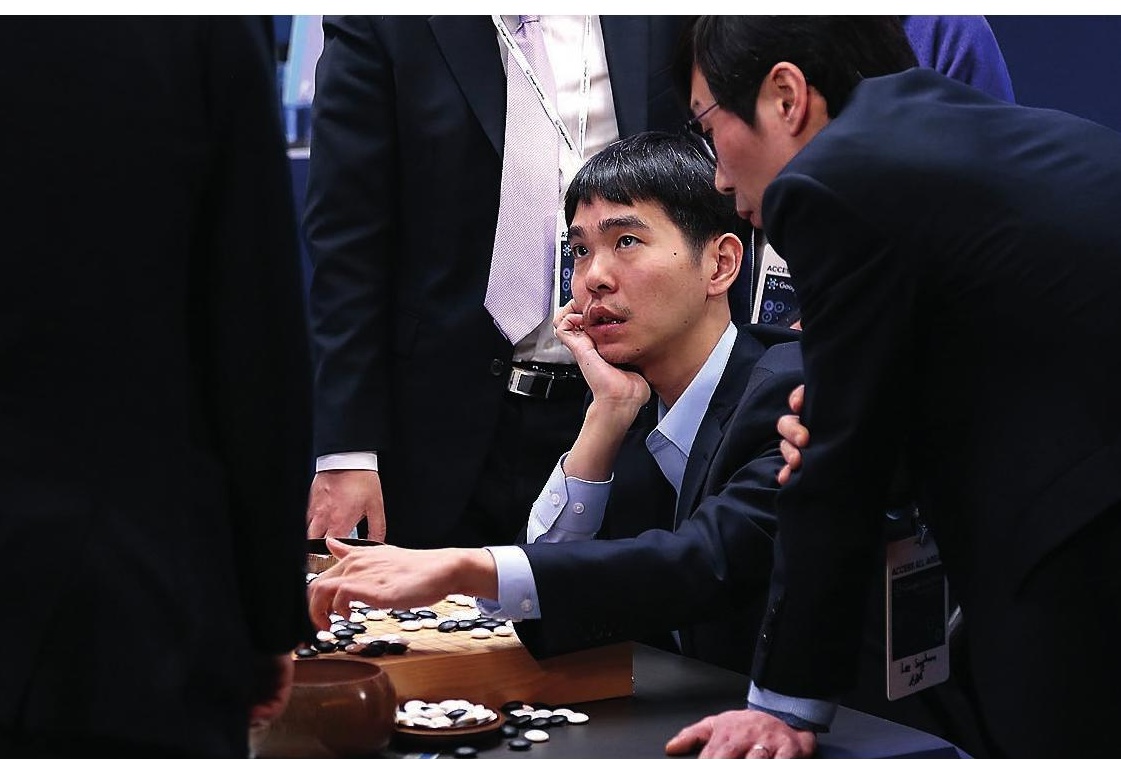

Go player Lee Sedol reviews a match against artificial intelligence.

\section{MIND GAMES}

In January, a computer program beat a world-class human player at the ancient game of Go for the first time. But the ultimate showdown was in March, when the artificial intelligence (AI), called AlphaGo, trounced Lee Sedol - one of the world's top players. The AI, developed by the Google-owned company DeepMind in London, opened with three consecutive wins in the five-round tournament. Lee took the fourth game and nearly won game five, but AlphaGo triumphed.

In October, DeepMind researchers debuted another AI, one capable of navigating the London Underground without any previous knowledge. The sophisticated program combined memory with the ability to learn from experience. This brought AI a step closer to performing human-like tasks such as reasoning.

AI also helped to reduce errors in machine translation of languages by around $60 \%$, and aided physicists looking for new super materials. These advances were largely powered by deep learning, which harnesses huge data sets and a hierarchical, brain-like method of computing.

\section{CONTROVERSIAL CONCEPTION}

After decades of research, assisted-reproduction techniques that mix DNA from three people are bearing fruit. These procedures prevent children from inheriting metabolic diseases caused by flaws in mitochondria, the cell's energy-producing structures.

In September, researchers working in a Mexican clinic reported the birth of the first healthy baby conceived through one such procedure. A baby in China was also reportedly born using the same technique. And in October, a clinic in Ukraine announced that two previously infertile women had conceived through a similar procedure. On 15 December, following scientists' advice, the United Kingdom's Human Fertilisation and Embryology Authority said that the technique was ready for clinical use, which could start as soon as 2017.

Written by Alison Abbott, Declan Butler, Davide Castelvecchi, Daniel Cressey, Elizabeth Gibney, Heidi Ledford, Jane J. Lee, Lauren Morello, Sara Reardon, Jeff Tollefson and Alexandra Witze. 


\section{CORRECTIONS}

The graphic in the 2016 News Review

(Nature 540,496-499; 2016) erroneously

said that the NIH was getting behind preprint

publishing. It is in fact a consortium funded

by the $\mathrm{NIH}$ that is mandating the practice. 